\title{
Influence of curing age on high-temperature properties of additive manufactured geopolymer mortar
}

\author{
Xiaohong Yin ${ }^{1,2}$, Xiaodong Wang ${ }^{1,2,3, *}$, Yuan Fang ${ }^{1,2, *}$, Zhu Ding ${ }^{1,2}$ \\ ${ }^{1}$ Guangdong Provincial Key Laboratory of Durability for Marine Civil Engineering, Shenzhen University, Shenzhen, Guangdong, 518060, \\ China \\ ${ }^{2}$ College of Civil and Transportation Engineering, Shenzhen University, Shenzhen, Guangdong, 518060, China \\ ${ }^{3}$ Centre for Smart Infrastructure and Digital Construction, Faculty of Science, Engineering and Technology, Swinburne University of \\ Technology, 3122 Melbourne, Australia
}

\begin{abstract}
Some researches have been conducted on the application of geopolymer in 3D printing. However, there is no publication about the high-temperature properties of 3D printed geopolymer made from fly ash, slag, and metakaolin. This paper presents the experimental research on the mechanical properties of 3D printed geopolymer after being exposed to elevated empratures. The effects of curing age on high-temperature properties are analyzed. The heating temperasures were $300{ }^{\circ} \mathrm{C}, 600{ }^{\circ} \mathrm{C}$, and $900{ }^{\circ} \mathrm{C}$, and the holding time was one hour. After exposure to temperatures, the flexural strength of 3D printed geopolymer exhibited different change trends with increasing curing age for different exposure temperatures. Before and after exposure to elevated temperature, the 3D printed geopolymer experienced significant anisotropic compressive strengths. The change trends of compressive strength at different exposure temperatures wit hincreasing curing ages were different from each other on different loading directions.
\end{abstract}

\section{Introduction}

The application of 3D printing technique in construction and building is attracting more and more attentions, and some researches and engineering projects have been conducted[1-10]. Geopolymer that is green, sustainable, and alternative to Portland cement has been formed as 3D printable cementitious materials[11-13]. Previous studies on $3 \mathrm{D}$ printable/printed geopolymer mainly focused on the preparation, fresh properties, interlayer adhesive strength, and hardened properties at ambient temperature.

Panda et al. [14] carried out an evaluation of the application potential of fly ash-based geopolymer for 3D printed large scale construction elements. The experimental results show that mechanical properties of 3D printed geopolymer exhibits anisotropic characters. Alghamdi et al. [15] prepared and characterized 3Dprinted foamed fly ash-based geopolymer for thermal insulation. Bong et al. [11] optimised 3D printable geopolymer cured at ambient temperature by investigating the impacts of type of hydroxide solution, type of silicate solution, and the mass ratio of silicate solution to hydroxide solution on workability, extrudability, shape retention ability, and mechanical properties. The experimental results show that the combination of sodium hydroxide and sodium silicate solutions with a $\mathrm{SiO}_{2} / \mathrm{N}_{2} \mathrm{O}$ ratio of 3.22 exhibited the most effective activating action for Slag-fly ash-based geopolymer. Lim et al. [16] created a hybrid reinforcement by entraining continuous steel cable into extruded mortar, and the experimental results show that the flexural strength of $3 \mathrm{D}$ printed geopolymer is increased by $290 \%$. Nematollahi et al. [17] found that only the compressive strength on perpendicular direction of additive manufactured fly ash-based geopolymer mortar can be improved by adding polypropylene fibres, and the flexural strength was improved due to the addition of fibres. Ohno and Li [18] designed fly ash-based Engineered Geopolymer Composite b integrating Design of Experiment, micromechanical modelling, and Material Sustainability Indices. Panda et al. [10] investigated the influences of printing time gap between layers, nozzle speed and nozzle standoff distance on the tensile bond strength of 3D printed fly ash-slag-silica fume-based geopolymer, and found that the bond strength is influenced by materials strength development rate and printing parameters. Panda et al. [19] investigated the fresh and hardened properties of 3D printed fly ash-slag-silica fume-based geopolymer, and found that silica fume significantly affected the fresh properties, and slag resulted in higher early strength.

The mechanical properties of cementitious materials after high temperature exposure are important aspects of concern for application in the building and construction. However, no publication about the high-temperature properties of 3D printed geopolymer is found. This paper investigates the flexural and compressive strength of different loading directions after exposure to $300{ }^{\circ} \mathrm{C}$, $600{ }^{\circ} \mathrm{C}$, and $900{ }^{\circ} \mathrm{C}$. 


\section{2 materials and methods}

2.1 Materials
The chemical compositions of fly ash (FA), slag and metakaolin used to prepare geopolymer in this study are listed in Table 1. The chemical compositions are measured using X-ray Fluorescence Spectrometer (XRF). The activator was commercial sodium silicate solution with a modulus of 2.0 and solid content of $40.1 \%$ by weight.

Table1. Chemical analysis of raw materials (wt $\%$ )

\begin{tabular}{ccccccccccc}
\hline Composition & $\mathrm{SiO}_{2}$ & $\mathrm{CaO}$ & $\mathrm{Al}_{2} \mathrm{O}_{3}$ & $\mathrm{MgO}$ & $\mathrm{SO}_{3}$ & $\mathrm{TiO}_{2}$ & $\mathrm{Fe}_{2} \mathrm{O}_{3}$ & $\mathrm{~K}_{2} \mathrm{O}$ & $\mathrm{MnO}$ & $\mathrm{O}$ thers \\
\hline Fly ash & 52.09 & 5.18 & 33.07 & 1.22 & - & 0.88 & 3.56 & 1.88 & - & 2.12 \\
Slag & 27.5 & 44.60 & 13.20 & 8.72 & 2.05 & 1.36 & 0.76 & 0.43 & 0.43 & 0.95 \\
Metakaolin & 47.4 & 0.39 & 41.6 & - & 0.085 & 1.88 & 2.89 & & 0.28 & 5.475 \\
\hline
\end{tabular}

\subsection{Preparation of 3D printed geopolymer mortar specimens}

First, 3D printable geopolymer mortar was prepared by mixing fly ash, slag, metakaolin, sodium silicate solution, water, superplasticizer, and hydroxypropyl methylcellulose (HPMC). The ratio of binder composition by mass is fly ash : slag : metakaolin $=3: 4: 3$. The sandto-binder ratio is 1.75 by mass. The sodium silicate solution and water dosage are 0.36 and 0.112 respectively by the total mass of binder. Both the HPMC and superplasticizer dosage is 0.01 by the mass of binder.

Once prepared, the 3D printable geopolymer mortar was placed into feed bin of $3 \mathrm{D}$ printer. Then the $3 \mathrm{D}$ printer was controlled by computer, and the mortar was extruded and deposited according to the model. The layer height was set as $14 \mathrm{~mm}$, and the extruded and deposited layers had a width of $52 \mathrm{~mm}$. the $3 \mathrm{D}$ printed geopolymer had three layers. After finishing printing, the printed samples were covered with plastic film. After cured for 23 hours, $40 \mathrm{~mm} \times 40 \mathrm{~mm} \times 160 \mathrm{~mm}$ specimens were extracted from printed filaments. Then, the specimens were cured at $20 \pm$ $2{ }^{\circ} \mathrm{C}$, and $\geq 95 \%$ relative humidity.

\subsection{High temperature exposure}

A electric resistance furnance was used to conduct the high temperature exposure test. The heating temperatures were set up to $300{ }^{\circ} \mathrm{C}, 600{ }^{\circ} \mathrm{C}$, and $900{ }^{\circ} \mathrm{C}$, and the holding time was one hour. The furnance was heated at the target temperature in advance. Then, the 3D printed geopolymer specimens cured for $1 \mathrm{~d}, 3 \mathrm{~d}, 7 \mathrm{~d}$, and $28 \mathrm{~d}$ were placed into furnance.

\subsection{Flexural and compressive strength}

The 3D printed geopolymer specimens before and after high temperature exposure were subjected to flexural and compressive strength. The loading rate was $50 \mathrm{~N} / \mathrm{s}$ during flexural strength test. The loading rate of compressive strength test was $2.4 \mathrm{KN} / \mathrm{s}$. The compressive strength of $3 \mathrm{D}$ printed geopolymer was measured on three loading directions, in terms of perpendicure to interface plane, longitudinal and lateral (Fig. 1).

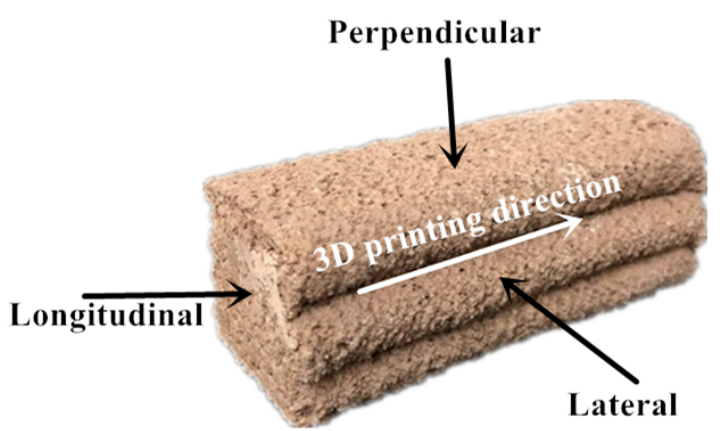

Fig. 1. Testing directions for the compressive strength test

\section{Results and discussion}

\subsection{Flexural strength}

Fig. 2 plots the flexural strength before and after exposure to high temperature against curing age. As shown in Fig. 2 , curing ages exhibit different influences on flexural strength after exposure to different temperatures. For specimens ta $20{ }^{\circ} \mathrm{C}$ without exposure to elevated temperature, the flexural strength increased with increasing curing ages, and a very slow increase rate was observed during curing age between $3 \mathrm{~d}$ and $7 \mathrm{~d}$. After exposure to $300{ }^{\circ} \mathrm{C}$, the flexural strength first increased from $1 \mathrm{~d}$ to $7 \mathrm{~d}$, and then slightly decreased at $28 \mathrm{~d}$. After exposure to $600{ }^{\circ} \mathrm{C}$, the flexural strength increased with increasing curing age with a decreasing growth rate. After exposure to $900{ }^{\circ} \mathrm{C}$, the flexural strength increased first from $1 \mathrm{~d}$ to $3 \mathrm{~d}$, and then decreased from $3 \mathrm{~d}$ to $28 \mathrm{~d}$. It is notable that, from $3 \mathrm{~d}$ to $7 \mathrm{~d}$, flexural strength had a significant increase after exposure to $300{ }^{\circ} \mathrm{C}$ and $600{ }^{\circ} \mathrm{C}$, but decreased after exposure to $900{ }^{\circ} \mathrm{C}$. After exposure to $300{ }^{\circ} \mathrm{C}, 600{ }^{\circ} \mathrm{C}$, and $900{ }^{\circ} \mathrm{C}$, the flexural strength decreased from $7 \mathrm{~d}$ to $28 \mathrm{~d}$. 


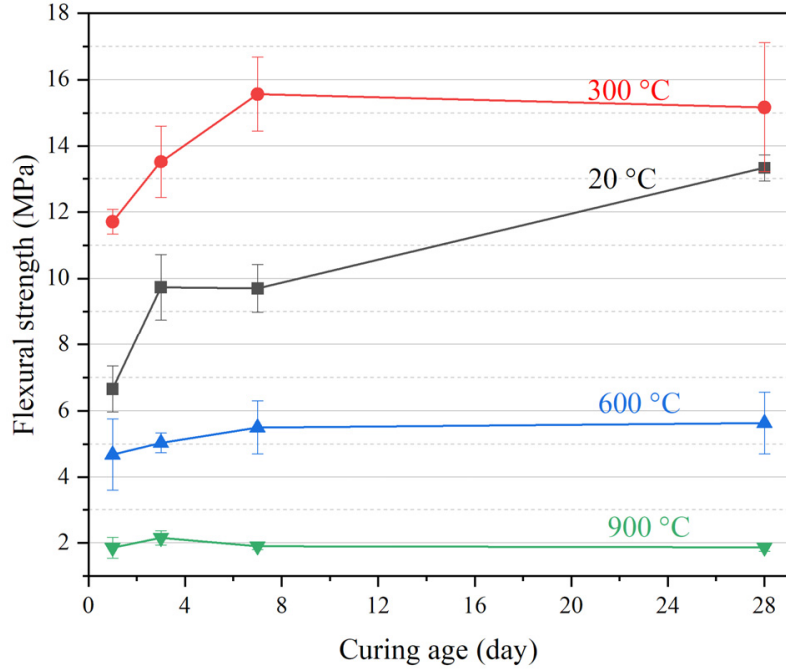

Fig. 2. Flexural strength of 3D printed geopolymer cured for different ages before and after high temperature exposure.

\subsection{Compressive strength}

Fig. 3 shows the plots of compressive strength measured on three loading direction before and after high temperature exposure against curing age. As shown in Fig. 3 , the influences of curing age on compressive strength depend on exposure temperatures and compression loading directions.

For 3D printed geopolymer specimens at $20{ }^{\circ} \mathrm{C}$ before exposure to high temperature, the increase rate was different on different loading directions. On perpendicular direction, the compressive strength experienced a slight increase between 1d and $3 \mathrm{~d}$, and a significant increase from $3 \mathrm{~d}$ to $7 \mathrm{~d}$. In contrast, on longitudinal direction, compressive strength showed a significant increase from $1 \mathrm{~d}$ to $3 \mathrm{~d}$, and a slight increase between $3 \mathrm{~d}$ and $7 \mathrm{~d}$. However, on lateral direction, compressive strength experienced a significant increase both from $1 \mathrm{~d}$ to $3 \mathrm{~d}$ and from $3 \mathrm{~d}$ to $7 \mathrm{~d}$.

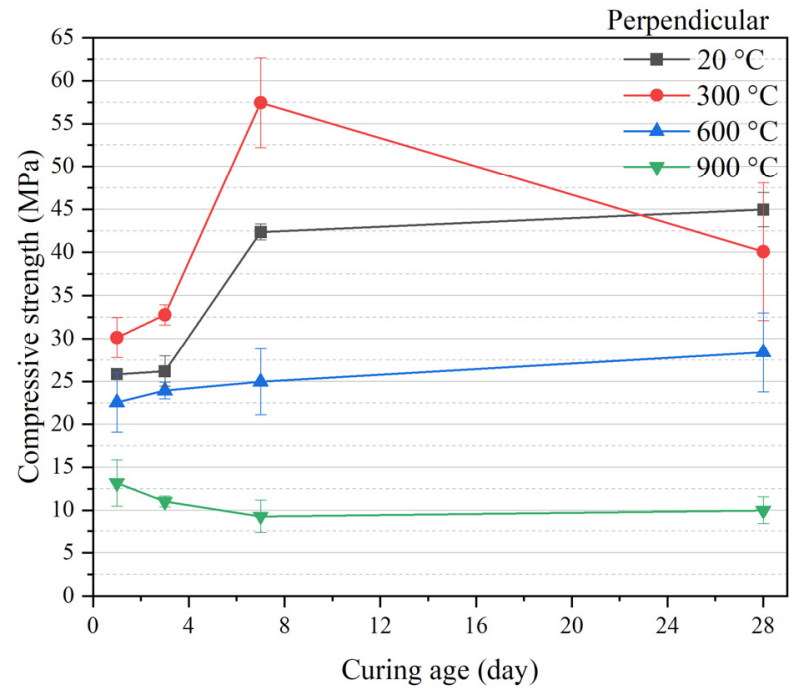

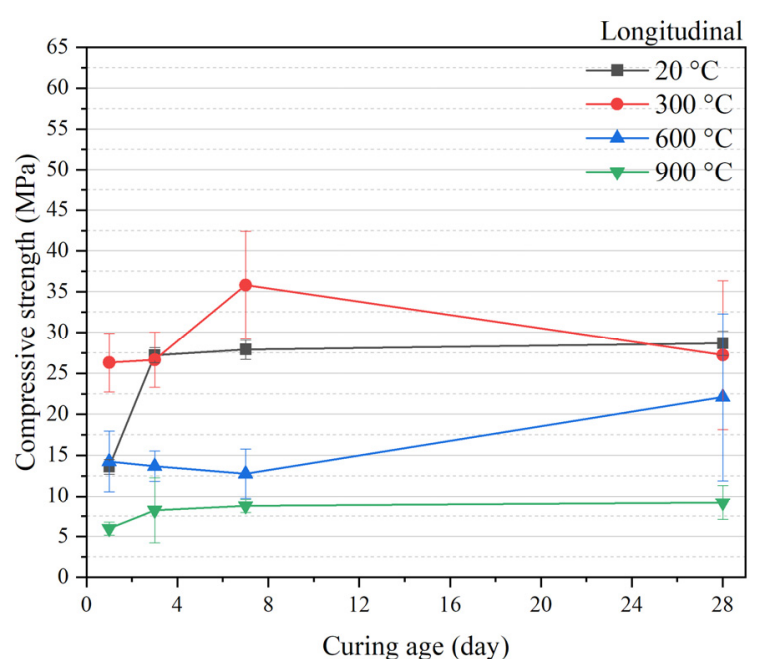

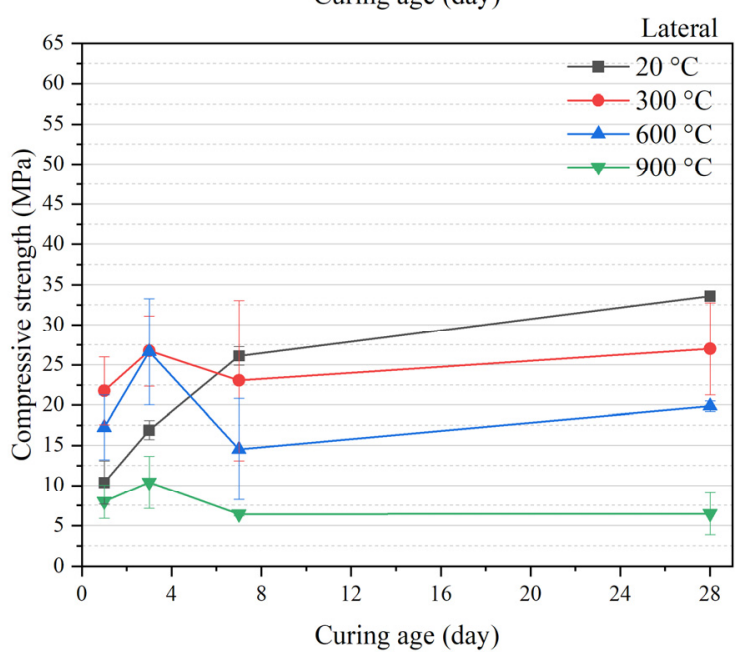

Fig. 3. Compressive strength of 3D printed geopolymer on different loading directions: perpendicular, longitudinal, and lateral.

For 3D printed geopolymer specimens at $300{ }^{\circ} \mathrm{C}$, the compressive strength exhibited similar change trends on perpendicular and longitudinal directions, by showing increase between $1 \mathrm{~d}$ and $7 \mathrm{~d}$, and decrease between $7 \mathrm{~d}$ and 28d. However, on lateral loading direction, the compressive strength increased between $1 \mathrm{~d}$ and $3 \mathrm{~d}$, then decreased between $3 \mathrm{~d}$ and $7 \mathrm{~d}$, after that an increase was observed between $7 \mathrm{~d}$ and $28 \mathrm{~d}$.

After exposure to $600{ }^{\circ} \mathrm{C}$, the compressive strength increased continuously from $1 \mathrm{~d}$ to $28 \mathrm{~d}$ on perpendicular direction. However, on longitudinal direction, the compressive strength decreased first between $1 \mathrm{~d}$ and $7 \mathrm{~d}$, and then increased between $7 \mathrm{~d}$ and $28 \mathrm{~d}$. On lateral direction, a complex change trend in compressive strength was observed by showing increase between $1 \mathrm{~d}$ and $3 \mathrm{~d}$, decrease between $3 \mathrm{~d}$ and $7 \mathrm{~d}$, and increase between $7 \mathrm{~d}$ and $28 \mathrm{~d}$.

After exposure to $900{ }^{\circ} \mathrm{C}$, the compressive strength on perpendicular direction increased first between $1 \mathrm{~d}$ and $7 \mathrm{~d}$, then increased slightly between $7 \mathrm{~d}$ and $28 \mathrm{~d}$. However, on longitudinal direction, the compressive strength increased continuously between $1 \mathrm{~d}$ and $28 \mathrm{~d}$. On lateral direction, the compressive strength experienced an increase from $1 \mathrm{~d}$ to $3 \mathrm{~d}$, a drastic decrease from $3 \mathrm{~d}$ to $7 \mathrm{~d}$, and a slight increase from $7 \mathrm{~d}$ to $28 \mathrm{~d}$. 


\section{Conclusions}

The flexural strength and compressive strength tested on three directions of 3D printed geopolymer before and after exposure to high temperature. the $3 \mathrm{D}$ printable geopolymers mortar were prepared from fly ash, slag, and metakaolin, activated by sodium silicate solution. The 3D printed geopolymers were cured for $1 \mathrm{~d}, 3 \mathrm{~d}, 7 \mathrm{~d}$, and $28 \mathrm{~d}$. The $3 \mathrm{D}$ printed geopolymers were heated at $300{ }^{\circ} \mathrm{C}$, $600{ }^{\circ} \mathrm{C}$, and $900{ }^{\circ} \mathrm{C}$ for one hour. The compressive strength shows significant anisotropy for specimens cured for all designed ages and heating at all questioned temperatures. The flexural strength exhibits different change trends with curing age before and after exposure to different temperatures. The change trends of compressive strength with increasing curing ages is dependent of heating temperatures.

\section{References}

1. Agusti-Juan, I.; G. Habert, Environmental implications and opportunities of digital fabrication. In Sustainable Built Environment (SBE) Regional Conference, Habert, G.; Schlueter, A., Eds. Zurich, SWITZERLAND, 2016; pp 304-308,10.3218/3774$6 \_49$.

2. Alghamdi, H.; S. A. O. Nair; N. Neithalath. (2019)Insights into material design, extrusion rheology, and properties of 3d-printable alkaliactivated fly ash-based binders. Materials \& Design, 167.

3. Bajpayee, A.; M. Farahbakhsh; U. Zakira; A. Pandey; L. Abu Ennab; Z. Rybkowski; M. K. Dixit; P. A. Schwab; N. Kalantar; B. Birgisson; S. Banerjee. (2020)In situ resource utilization and reconfiguration of soils into construction materials for the additive manufacturing of buildings. Frontiers in Materials, 7.

4. Barnett, E.; C. Gosselin. (2015)Large-scale 3d printing with a cable-suspended robot. Additive Manufacturing, 7: 27-44.

5. Beyhan, F.; S. A. Selcuk, 3d printing in architecture: One step closer to a sustainable built environment. In Proceedings of $3 \mathrm{rd}$ international sustainable buildings symposium, Firat, S.; Kinuthia, J.; AbuTair, A., Eds. 2018; Vol. 6, pp 253-268.

6. Camacho, D. D.; P. Clayton; W. J. O'Brien; C. Seepersad; M. Juenger; R. Ferron; S. Salamone. (2018)Applications of additive manufacturing in the construction industry - a forward-looking review. Automat Constr, 89: 110-119.

7. Ding, Z.; X. Wang; J. Sanjayan; P. X. W. Zou; Z.-K. Ding. (2018)A feasibility study on hpmc-improved sulphoaluminate cement for $3 \mathrm{~d}$ printing. Materials, 11.

8. Yin, X.; K. Liu; S. Zheng; K. Zhuang; X. Wang; Y. Fang; Z. Ding. (2020)3d printable 'just-add-water glass and water'geopolymer-an experimental research based on extrusion-based $3 \mathrm{~d}$ printing practices. $M S \& E$, 780: 042044.
9. Sun, X.; Q. Wang; H. Wang; L. Chen. (2020)Influence of multi-walled nanotubes on the fresh and hardened properties of a $3 \mathrm{~d}$ printing pva mortar ink. Constr. Build. Mater., 247: 118590.

10. Panda, B.; S. C. Paul; N. A. N. Mohamed; Y. W. D. Tay; M. J. Tan. (2018)Measurement of tensile bond strength of $3 \mathrm{~d}$ printed geopolymer mortar. Measurement, 113: 108-116.

11. Bong, S. H.; B. Nematollahi; A. Nazari; M. Xia; J. Sanjayan. (2019)Method of optimisation for ambient temperature cured sustainable geopolymers for $3 \mathrm{~d}$ printing construction applications. Materials, 12.

12. Li, Z.; L. Wang; G. Ma. (2020)Mechanical improvement of continuous steel microcable reinforced geopolymer composites for $3 \mathrm{~d}$ printing subjected to different loading conditions. Compos Part B-Eng, 187.

13. Ma, G.; Z. Li; L. Wang; G. Bai. (2019)Micro-cable reinforced geopolymer composite for extrusion-based 3d printing. Mater. Lett., 235: 144-147.

14. Panda, B.; S. C. Paul; L. J. Hui; Y. W. D. Tay; M. J. Tan. (2017)Additive manufacturing of geopolymer for sustainable built environment. Journal of Cleaner Production, 167: 281-288.

15. Alghamdi, H.; N. Neithalath. (2019)Synthesis and characterization of 3d-printable geopolymeric foams for thermally efficient building envelope materials. Cem. Concr. Compos., 104.

16. Lim, J. H.; B. Panda; P. Quang-Cuong. (2018)Improving flexural characteristics of $3 \mathrm{~d}$ printed geopolymer composites with in-process steel cable reinforcement. Constr. Build. Mater., 178: 3241.

17. Nematollahi, B.; P. Vijay; J. Sanjayan; A. Nazari; M. Xia; V. N. Nerella; V. Mechtcherine. (2018)Effect of polypropylene fibre addition on properties of geopolymers made by $3 \mathrm{~d}$ printing for digital construction. Materials, 11.

18. Ohno, M.; V. C. Li. (2018)An integrated design method of engineered geopolymer composite. Cem. Concr. Compos., 88: 73-85.

19. Panda, B.; C. Unluer; M. J. Tan. (2018)Investigation of the rheology and strength of geopolymer mixtures for extrusion-based 3d printing. Cem. Concr. Compos., 94: 307-314. 